\title{
Pioneers of Islamic Medicine
}

$\mathrm{T}$ here were certain personalities in the history of Islamic medicine that not only shaped its future but also systematized it, codified it, and made it available to the physicians and medical students of the day. This was made available not only for their medical instruction and education, but also for application in the daily practice of their profession. Moreover, it was through the efforts of these pioneers that the extant medicine at their time was collected from various parts of the world, translated into the languages of the populace, and compiled into encyclopedias, which were to become standard works of reference for centuries to come.

Medicine owes much to these individuals for having the foresight of preserving the medical knowledge of the ancient physicians. But to claim, as some Orientalists have done, that these great personalities were mere translators and copyists and documentators, would be a statement of uninformed scholarship. Because recent research has proven beyond doubt that the contributions made by the physicians, scientists, and scholars of the Muslim world contained new observations, discoveries, applications, and innovations that did change the way medicine was practiced during their times and in times to come.

The "Pioneers of Islamic Medicine" series to be presented in our journal for the next several issues will profile some of these great personalities and give the reader a brief biographical sketch of these great physicians of the Islamic period. Although much has been written about them in various books, journals and periodicals, this important knowledge has been scattered and dispersed in many languages and many lands. Their manuscripts are spread out in various parts of the world and only recently has an effort been made to collect their works in one comprehensive collection. For this noble effort we are indeed indebted to one individual, Dr. Fuat Sezgin, and to the Institute for the History of Arabic-Islamic Science at the Johann Wolfgang Goethe University, Frankfurt am Main, Germany. His brilliant scholarship has earned him the famous King Faisal Prize for academic excellence and lifetime achievement.

To our astute readers and research students, especially the young among them, this will then serve as a basis for reference and further research into the works and contributions that these great individuals made to the art and science of medicine. This has been one of main aims of the International Institute of Islamic Medicine (IIIM) when it was formulated in 1992 by the Islamic Medical Association of North America. We encourage our young readers to take the challenge of this esoteric scholarship further, by diligent research in our past achievements, so that we can continue to strive further in the future, with renewed vigor and energy in the true spirit that these pioneers represent and inspire.

\author{
Husain Nagamia, MD FRCS (England and Edinburgh) \\ Chairman \\ International Institute of Islamic Medicine (IIIM) \\ Chief Emeritus, Cardiovascular Thoracic Surgery \\ Cardiac Institute of Florida, Tampa General Hospital \\ Clinical Assistant Professor of Surgery \\ University of South Florida Medical School \\ Tampa, Florida \\ Associate Editor, JIMA
}

